\title{
Analytical Methods for Quantification of Vitamin D and Implications for Research and Clinical Practice
}

\author{
CAROLINE S. STOKES ${ }^{1}$, FRANK LAMMERT $^{1}$ and DIETRICH A. VOLMER ${ }^{2}$ \\ ${ }^{1}$ Department of Medicine II, Saarland University Medical Center, Saarland University, Homburg, Germany; \\ ${ }^{2}$ Institute of Bioanalytical Chemistry, Saarland University, Saarbrücken, Germany
}

\begin{abstract}
A plethora of contradictory research surrounds vitamin $D$ and its influence on health and disease. This may, in part, result from analytical difficulties with regard to measuring vitamin D metabolites in serum. Indeed, variation exists between analytical techniques and assays used for the determination of serum 25-hydroxyvitamin D. Research studies into the effects of vitamin $D$ on clinical endpoints rely heavily on the accurate assessment of vitamin D status. This has important implications, as findings from vitamin D-related studies to date may potentially have been hampered by the quantification techniques used. Likewise, healthcare professionals are increasingly incorporating vitamin $D$ testing and supplementation regimens into their practice, and measurement errors may be also confounding the clinical decisions. Importantly, the Vitamin D Standardisation Programme is an initiative that aims to standardise the measurement of vitamin D metabolites. Such a programme is anticipated to eliminate the inaccuracies surrounding vitamin D quantification.
\end{abstract}

The most frequently studied vitamin D metabolite is 25 hydroxyvitamin $\mathrm{D}$, which is usually determined from serum or plasma as the aggregate concentration of 25-hydroxyvitamin $\mathrm{D}_{3}$ and 25-hydroxyvitamin $\mathrm{D}_{2}$, to obtain this generally accepted biomarker for vitamin D status. Contradictory research surrounds vitamin $\mathrm{D}$ and its influence on health and disease (1). Numerous studies have reported associations between vitamin $\mathrm{D}$ status and disease risk, however, they are compounded by studies that do not corroborate such correlations (2-7). Likewise, the enthusiasm from results of clinical intervention studies demonstrating efficacious

Correspondence to: Dietrich A. Volmer, Institute of Bioanalytical Chemistry, Saarland University, Saarbrücken, Germany. E-mail: dietrich.volmer@mx.uni-saarland.de

Key Words: Epimer, 25-hydroxyvitamin D, mass spectrometry, standardisation, Vitamin D Standardisation Programme. properties of vitamin D supplementation is tempered by studies reporting a lack of such effects $(3,4,8,9)$.

These discrepancies may, in part, be influenced by systematic 'errors' such as those that result from a lack of consensus surrounding what constitutes optimal serum concentrations of the status marker. Adequate serum 25hydroxyvitamin $\mathrm{D}$ concentrations have been suggested to be $20 \mathrm{ng} / \mathrm{ml}(50 \mathrm{nmol} / \mathrm{l})$ (10) and $30 \mathrm{ng} / \mathrm{ml}(75 \mathrm{nmol} / \mathrm{l})(11)$. Furthermore, it has also been pointed out that the optimal cutoff might in fact be disease dependent (12).

Perhaps even more importantly, when considering systematic influences and the aforementioned conflicting findings, is the large variability in laboratory measurements of vitamin D status. Specifically, a 15-20\% variability between different quantification methods has been reported (10).

In the pharmaceutical industry, careful validations of analytical procedures for drugs are routinely performed as prescribed in the monographs of the pharmacopoeia, including the use of reference materials and system suitability testing. Method harmonisation has not yet been fully established in the vitamin D field, but an important initiative is currently underway to standardise the measurement of vitamin D metabolites (13) as a consequence of the large variability seen in the results of vitamin D analyses.

This overview focuses on the issues surrounding variability in vitamin $\mathrm{D}$ quantification methods and discusses the implications of these inconsistencies for research studies as well as for healthcare professionals in the clinical setting. Importantly, this overview is not exhaustive as representative articles were chosen to illustrate key issues of measurement variability.

\section{Variability in Vitamin D Quantification}

This section briefly summarises common assays used in the analytical determination of 25-hydroxyvitamin $\mathrm{D}_{3}$, followed by a description of how these assays might be influenced by other sample matrix components or external sources, leading 
to systematic errors and method bias. The tight binding of 25hydroxyvitamin $\mathrm{D}_{3}$ to vitamin $\mathrm{D}$ binding protein (DBP) during circulation of blood adds a further complication and source of variation. Importantly, problems in accuracy will generally lead to systematic errors and thus may cause variability of results between different measurement techniques.

Several methods have been routinely used in the quantification of vitamin $\mathrm{D}$, including competitive proteinbinding (CPB) assays, radioimmunoassays (RIA), chemiluminescence immunoassays (CLIA), liquid chromatography (LC) with UV detection, and liquid chromatography-mass spectrometry (LC-MS) or tandem mass spectrometry (LC-MS/MS). In clinical practice, CPB, RIA and CLIA remain the most widely applied assays. These are available in kit form and can be readily automated in a highthroughput fashion, allowing hundreds of samples to be measured per hour. The literature often describes the antibody's reactivity for 25-hydroxyvitamin $\mathrm{D}_{2}$ and 25hydroxyvitamin $\mathrm{D}_{3}$ as being equal for the two vitamers, with no affinity for 3-epi-25-hydroxyvitamin $\mathrm{D}_{3}$. There are opposing opinions on this issue, however, and some reports point to selectivity issues between vitamers and epimers (1419). Epimers of 25-hydroxyvitamin $D_{3}$ originate from stereochemical inversion of the hydroxyl group at C-3 of the vitamin $\mathrm{D}$ backbone $(3 \beta \rightarrow 3 \alpha)$ and are discussed further below. Importantly, the complete absence of binding of the 3epi-25-hydroxyvitamin $D_{3}$ species has not been fully confirmed for all analyser platforms (20-23). Additionally, possible affinities of other vitamin D metabolites to the antibodies used in assays, which may also differ between platforms, need to be investigated further. DBP release of 25hydroxyvitamin $\mathrm{D}_{3}$ during sample preparation - which is required for immunoassays - may cause additional variation as a result of different sample preparation procedures between assay platforms.

Liquid chromatographic methods have been frequently applied in the past (24), mostly using UV detection. The analytical specify of UV detection is limited, but the primary advantage of LC-based methods is their ability to separate the different vitamin D species, allowing individual quantification and removal of interfering species (25). A simple example is the specific assessment of vitamin $\mathrm{D}_{2}$ supplementation in patients after separating 25-hydroxyvitamin $\mathrm{D}_{2}$ and 25-hydroxyvitamin $\mathrm{D}_{3}$ (26).

LC-MS offers additional advantages by measuring mass-tocharge ratios $(\mathrm{m} / \mathrm{z})$ as a detection feature, particularly in combination with tandem mass spectrometry (MS/MS). The latter provides information on structure-specific elements of the molecules after breaking the ionised molecules into fragments during MS/MS. The other inherent advantage of MS-based techniques is that they can account for protein binding by implementing isotope standards of the vitamin D species as internal standards.
In a recent discussion on LC-MS/MS techniques for vitamin D analysis, we pointed out that ideally, a universal gold standard assay would permit the quantification at highthroughput levels, with excellent reproducibility and accuracy in different laboratories (27). At the same time, it should be simple to perform. We also pointed out that, unfortunately, such an assay currently does not exist (27). Nevertheless, today LC-MS/MS is often described as such a gold-standard assay in the literature. Therefore, it is important to understand that MS exhibits inherent sources of variation and error, which must be uncovered and corrected for if possible. These include interferences from matrix effects, chemical epimers, mass spectral selectivity issues from isomeric and isobaric interferences, influence of different ionisation sources [in particular, atmospheric pressure chemical ionisation (APCI) versus electrospray ionisation (ESI)], general sensitivity limitations due to limited ionisation efficiency, and the role of the mass analyser platform. Technical descriptions of ionisation techniques and mass analyser platforms for vitamin $\mathrm{D}$ and their influence on specificity is beyond the scope of this article and the reader is referred to a recent discussion on the subject (28).

What is important to discuss here, however, are interference-related limitations of specificity of LC-MS/MS, which can cause method-related variability in reported 25hydroxyvitamin $\mathrm{D}_{3}$ results. Of particular concern are the detrimental contributions of other chemical compounds to the measured 25-hydroxyvitamin $\mathrm{D}_{3}$ concentration, which primarily originate from co-ionised components contained in the sample extract, co-eluting isobaric molecules from endogenous and exogenous sources, and isomers such as the C-3 epimer.

Interferences from co-eluting components of the sample extract can trigger a phenomenon called ion suppression (29). This process describes the reduction (rarely enhancement) of the analyte's measured signal by other components which happen to enter the ion source at the same time and which are then preferentially ionised over the compound of interest. Stable isotope standards of 25-hydroxyvitamin $\mathrm{D}_{3}$ (usually a deuterated analog) correct for systematic errors from ion suppression, as long as protein binding of the isotopicallylabelled analogue is identical to that of 25-hydroxyvitamin $\mathrm{D}_{3}$ (30). Deuterated isotope standards are readily available for 25hydroxyvitamin $\mathrm{D}_{3}$ and several other vitamin $\mathrm{D}$ metabolites, but a dedicated deuterated standard has only recently become commercially available for the C3 epimer of 25hydroxyvitamin $\mathrm{D}_{3}$.

The second significant source of analytical error originates from co-elution of molecules with identical molecular weight, so-called isobaric compounds. The danger of these endogenous or exogenous isobaric components is that they have the potential to inflate the measured concentration for 25hydroxyvitamin $\mathrm{D}_{3}$. It was recently illustrated by Qi et al. that 
multiple isobaric compounds for 25-hydroxyvitamin $\mathrm{D}_{3}$ are present in human serum (31). While simple LC-MS methods can only correct for these molecules if sufficient selectivity is available from the chromatographic separation step, it has been shown that several of these are very difficult to separate by LC (31). Furthermore, there are many potential endogenous compounds with the same molecular weight as 25hydroxyvitamin $\mathrm{D}_{3}$. The application of MS/MS will remove many of these compounds if specific transitions are chosen in MS/MS data acquisition. Nevertheless, it has been demonstrated that even with MS/MS, several such interferences persist for 25hydroxyvitamin $\mathrm{D}_{3}$ determination. For example, we identified a technical lubricant introduced by the chromatographic system with virtually identical chromatographic and MS properties, which required an additional separation dimension via ion mobility spectrometry to eliminate (31). Importantly, highresolution MS using sufficiently high resolving powers will eliminate many ions from interfering molecules. Unfortunately, high-resolution mass spectrometers have not yet been routinely established in the quantitative determination of 25-hydroxyvitamin $\mathrm{D}_{3}(32,33)$.

Finally, detrimental interferences can also originate from isomers. Of particular interest are the two epimers of 25hydroxyvitamin $\mathrm{D}_{3}$ (vide supra). While the biological significance of the $3 \alpha$-epimer remains unknown, its potential to contribute to the level of 'normal' $3 \beta$-epi-25hydroxyvitamin $\mathrm{D}_{3}$ requires proper separation by chromatography prior to MS analyses, as the MS and MS/MS behaviours of both isomers are virtually identical. It was recently shown that the two epimers differ in their physicochemical properties, making it impossible to quantify both species using a single stable isotope standard (34). We recently described an LC-MS/MS assay for simultaneous quantification of both epimers using dedicated stable isotope standards for both species as well as chemical derivatisation to equalise the physicochemical behaviour of the two epimers $(35,36)$. It is worth pointing-out that while this procedure does provide accurate quantitative results for both species, the reported concentrations for the $3 \alpha$-epimer might slightly differ from those of other laboratories which use method calibrations based on the normal $3 \beta$-epi-25-hydroxyvitamin $\mathrm{D}_{3}$. Similarly to regular 25-hydroxyvitamin $\mathrm{D}_{3}$, analytical methods for the $3 \alpha$-epimer are not harmonised.

With respect to the measured concentrations and measurement errors, there is currently no agreement on the general importance of the $3 \alpha$-epimer and its role in total 25 hydroxyvitamin $\mathrm{D}_{3}$. Some studies have suggested negligible levels, e.g. (37) in adults, while others pointed to significantly overestimated concentrations if measured together, e.g. (34). Importantly, the $3 \alpha$-epimer concentration is usually very high in infants and it has therefore been suggested that an LCMS/MS method be used that separates the two species if samples are measured in patients younger than 1 year (37).
The above interference problems led Carter to suggest that isobaric interferences and the $3 \alpha$-epimer of 25hydroxyvitamin $\mathrm{D}_{3}$ were responsible for the persistent positive bias of LC-MS/MS in round-robin studies (38). Seemingly confirming this, Lai et al. reported that Diasorin Liaison assays returned much lower 25-hydroxyvitamin $\mathrm{D}_{3}$ concentrations than LC-MS/MS for serum samples of 813 participants of the Australian Multicentre Study of Environment and Immune Function (39). Almost immediately, these findings were questioned $(40,41)$, however, it was pointed out that the LC-MS/MS methodology used was not properly standardised against a National Institute for Standards and Technology (NIST) reference method and that "confounding metabolites (e.g. epimers and isobars) in a now 'out of date' LC-MS/MS method" were not properly considered. Couchman et al. showed that many variables in sample preparation, chromatography and LC-MS/MS ionisation/fragmentation must be considered when using LCMS/MS (42). The authors analysed results from a survey of 65 laboratories using samples provided by the international Vitamin D External Quality Assessment Scheme (DEQAS). The study highlighted an important consideration that is often entirely ignored when comparing established clinical assays such as CLIA or RIA with LC-MS/MS. The biomedical literature often simplifies MS assays to just 'LC-MS/MS'. This is the same, however, as saying that assays using a recombinant DBP or an antibody to detect 25-hydroxyvitamin $\mathrm{D}$ are the same, when in reality they may significantly differ. LC-MS/MS has multiple variables and parameters that will fundamentally alter selectivity. For example: choice of LC stationary phase selectivity, which may make vitamin D compounds co-elute or be separated; ionisation technique (APCI or ESI), which is gas or liquid phase-based ionisation, with differences of ionisation efficiency and spectrum of ionised interferences causing ion suppression; resolving power of the mass analyser, which can be limited to unit resolution (quadrupole) or be able to separate even close isobaric species (Orbitrap or Fourier-transform ion cyclotron resonance); and chemical derivatisation to alter the detection properties of vitamin D compounds completely.

\section{Standardisation of Vitamin D Measurement}

The above discussion clearly highlights the need for careful standardisation of vitamin D measurement procedures. Since 1989, proficiency testing exercises have been organised through DEQAS $(43,44)$, which have greatly reduced interlaboratory variability between the participating laboratories. Furthermore, the availability of certified standard reference materials (SRM) from the NIST has allowed clinical laboratories to validate their methods. The most recent NIST SRM is SRM 972a, which includes 25-hydroxyvitamin $\mathrm{D}_{3}$, 25-hydroxyvitamin $\mathrm{D}_{2}, 3 \alpha$-epi-25-hydroxyvitamin $\mathrm{D}_{3}$ as well 
as 24,25-dihydroxyvitamin $\mathrm{D}_{3}$ at different concentrations. These materials have reduced inter-laboratory imprecision of determination of total 25-hydroxyvitamin D (42).

The Vitamin D Standardisation Programme (VDSP) represents an international initiative established in 2010 to produce standardised serum 25-hydroxyvitamin D laboratory measurements. The aim of the VDSP is to produce a gold standard reference assay or to put forth standard measurement procedures developed by NIST, the University of Ghent and the Centers for Disease Control and Prevention (45-47). Their procedures are termed reference measurement procedures (RMP) and the goal is to enable future vitamin D studies (in addition to past studies, where possible) to be comparable, and foremost unbiased in terms of laboratory variability, in vitamin D quantification.

Moreover, such a standardisation scheme could be implemented in national surveys conducted regularly in many countries. Such surveys are used to decipher certain features of the population from which evidence-based guidelines are based on. They are also used to inform government policy and regulatory aspects. Consequently, the ability to analyse samples from existing studies or surveys holds importance. The concept of retrospectively standardising vitamin $\mathrm{D}$ values relies however on appropriate serum sampling storage. Indeed, studies to date have shown this approach to be worthwhile (48-52). Binkley et al. (53) further emphasized the importance of retrospective standardisation and not only focusing on standardised methods in current and future studies (53). The authors point out that the approximately 60,000 published articles on 25-hydroxyvitamin D since its discovery have nearly all used non-standardised methods for concentration measurements and that it is problematic to use guidelines based on data from unstandardised methods (54).

One of the first such studies used data from the Irish National Health/Nutrition Survey and re-analysed stored serum samples using the VSDP reference system and protocols. The authors observed prevalence rates for serum 25-hydroxyvitamin D concentrations below various thresholds to be significantly higher when using the VDSP system when compared to enzyme-linked immunosorbent assay (ELISA) measurements (48). For instance, when comparing serum 25hydroxyvitamin D of less than $12.5 \mathrm{ng} / \mathrm{ml}(30 \mathrm{nmol} / \mathrm{l})$, the prevalence rates for samples below this cut-off was significantly lower when using ELISA as compared to the VDSP protocols (6.5\% versus $11.4 \%$, respectively) (48). When analysing the samples with a standard LC-MS/MS approach, prevalence estimates were similar to the VDSP-obtained value $(11.2 \%)$. Thus, one consequence of such an established standardisation programme is that the true estimates of deficiency prevalence, as determined in national surveys, could be established. Furthermore, population trends in serum vitamin $\mathrm{D}$ concentrations over time could be more clearly defined and correlated with health and disease.
In research, greater reliability can be obtained in studies such as meta-analyses, which have the potential to produce more accurate results when including studies that have standardised serum 25-hydroxyvitamin D concentrations. A recent meta-analysis assessing the relationship between vitamin $\mathrm{D}$ and mortality using individual participant data also included standardised serum 25-hydroxyvitamin D values from 26,916 individuals, thus circumventing the potential bias introduced in such studies when using unstandardised vitamin $\mathrm{D}$ values, as discussed further in the next section (55).

\section{Implications for Research}

The variations in analytical techniques and assays described illustrate how systematic errors in vitamin D quantification may occur. This might have significant implications for research into vitamin D and its role in health and disease, which relies on the accurate assessment of vitamin D status (54). This area has recently been discussed in detail [see Lucas et al. (56)], hence this section only briefly describes how the variabilities in quantification of serum 25-hydroxyvitamin D concentrations could affect research studies.

In epidemiological settings, associations between vitamin $\mathrm{D}$ status and disease risk are frequently studied, often over a period of years. Confounders such as serum concentrations of epimer and large variability in vitamin D metabolite quantification are likely to impede true associations being found due to a lack of precision in 25-hydroxyvitamin D assessment. This is particularly the case for national surveys and longitudinal studies investigating correlations between certain diseases and serum 25-hydroxyvitamin D level, because in such studies, more than one serum vitamin $D$ value is often obtained from participants. This might also be problematic for clinical intervention studies, and can result in intra- and interindividual variability in laboratory vitamin D measurements and misrepresent trends in associations for vitamin D concentrations (52).

When, for instance, vitamin D deficiency is investigated in the context of chronic liver diseases, as a risk factor for disease initiation, progression, development of comorbidities and extrahepatic complications as well as for prognosis, several vitamin D measurements would be required at different time points, and limiting the variability of assay measurements is crucial. Moreover, studies in which participants are categorised according to vitamin D status (i.e. normal, insufficient, deficient, or severely deficient) or according to quantiles (based on the distribution of serum 25-hydroxyvitamin D in the study population) and then assessed with respect to various healthrelated endpoints, also run the risk of associations being obscured, due to inaccurate quantification of serum 25hydroxyvitamin D levels and misclassification of vitamin D status. 
Supplementation studies, e.g. in which patients who have serum 25-hydroxyvitamin D concentrations below a specified cut-off (e.g. $20 \mathrm{ng} / \mathrm{ml} ; 50 \mathrm{nmol} / \mathrm{l})$, are supplemented with vitamin D and followed up for health-specific effects, are a cause for concern if laboratory methods with large variability are used. The reduced accuracy might lead to patients receiving vitamin $\mathrm{D}$ supplements when in actual fact their serum 25-hydroxyvitamin D concentrations are above the target threshold for inclusion and hence supplementation. Moreover, variation in assays results might not allow the true within-person response to supplementation to be defined. These factors have important implications, especially as vitamin D replacement therapy has been shown to have a dose-response curve (57). The curve illustrates that patients who benefit the most from vitamin $\mathrm{D}$ supplementation are those that have the lowest serum concentrations of 25hydroxyvitamin D at baseline. Moreover, when a sufficient quantity of the vitamin D supplement is given to these patients, they climb up the response curve and improvements to their serum 25-hydroxyvitamin D concentrations follow. In contrast, patients receiving vitamin D supplements when baseline serum values are considered to be near to or within the normal range (described here as adequate stores in the body), do not experience benefit from the supplementation regimen. This is because vitamin D stores are already replenished. Consequently, misleading results, particularly null findings may occur, because the ability to assess the efficacy of vitamin D is compromised when these factors are not taken into consideration.

Meta-analyses based on vitamin D might also be affected by differences in serum vitamin D measurements (53). This is primarily because meta-analyses combine results from several homogenous studies to yield a pooled aggregate effect. The reliability of a particular meta-analysis thus hinges on the precision and accuracy of the included studies. The fact that studies likely vary in terms of laboratories and methods used to quantify serum vitamin D concentrations is certainly a limitation. Moreover, meta-analyses often include data from studies that classified patients according to cut-offs or quantiles for vitamin D status. This increases the risk of null findings, given the heterogeneity in such classifications as a result of laboratory variability in vitamin D measurements, and because the quantiles themselves may not be harmonious between study populations (56).

Should vitamin D indeed be proven to be a mediator in disease, it presents a cost-effective option with low risk of side-effects. Nevertheless, because of the discrepancies in laboratory measurements of vitamin $\mathrm{D}$, findings from intervention studies may also need to be interpreted with caution. Lucas et al. (56) recently suggested study designs should consider the accuracy or precision issues in vitamin D assays. Where variability is known to exist, it might be worth considering freezing additional serum samples from the same study patients and testing them in a single batch once the study has ended. This is rarely reported in research studies, although some studies have reduced such bias by including a second reliable method to quantify vitamin D concentrations in all or a subset of samples (58).

\section{Implications for Clinical Practice}

Demand for serum 25-hydroxyvitamin D measurements in the clinical setting have increased dramatically in recent years (59). The purpose is primarily to determine whether supplementation therapy is required. The treatment plan for clinicians' using a treat-to-target approach might be complicated by the discrepancies amongst guidelines defining optimal vitamin D concentrations $(10,11)$. Moreover, inaccurate quantification of the status marker can lead to some patients being denied supplementation with vitamin $\mathrm{D}$ due to imprecise assays, which tend to overestimate serum levels. Likewise, supplementation might be initiated in patients who do not require it, as a result of assays biased being towards lower values. Thus, inaccuracies in determining the vitamin D status can have implications for patient care.

The risk of assays producing lower than normal readings (i.e. finding a patient to have serum 25-hydroxyvitamin D concentrations that are lower than they actually are) as opposed to higher than normal is reported as being more likely to occur (60). This is because many commercial and clinical laboratories use automated immunoassays, and these are generally known to produce lower values when compared to LC-MS/MS (see discussion above). This suggests that the risk of overtreatment with vitamin $\mathrm{D}$ is greater than undertreatment. Besides the cost implications of this, health implications also need to be considered because vitamin D is a fat-soluble vitamin and as such is stored in the body. This means that it can be toxic if the serum level becomes elevated (e.g. $>150 \mathrm{ng} / \mathrm{ml})(61)$.

Steps can be taken, however, to minimise the above confounders in the clinical setting. For example, clinicians should conduct a follow-up blood measure of serum 25hydroxyvitamin D concentration 3 to 6 months after the initiation of vitamin D supplementation. Since the assays come at considerable costs, appropriate selection of patients who would benefit from vitamin D testing should be applied. Moreover, deciding when to test the vitamin D level is also important. Zhao et al. state that measuring the serum 25-hydroxyvitamin D level in winter does not represent the 'year-round' vitamin D status (59). Thus by default, patients with concentrations approaching sufficient levels during winter do not necessarily need supplements. On the contrary, vitamin D supplementation should be initiated in patients with a serum 25-hydroxyvitamin $\mathrm{D}$ concentration below the sufficient level when measured during middle to late summer months, as the level is likely to decrease further in winter. 
Moreover, including serum parathyroid hormone (PTH) in the diagnostic work-up may have additional value, since many patients develop secondary hyperparathyroidism in the setting of vitamin D deficiency (62). This is because of the inverse association between serum 25-hydroxyvitamin D and PTH concentration. Moreover, one indicator that vitamin D sufficiency is biochemically achieved is normalisation of the PTH level $(11,62)$. In addition, including serum calcium and phosphate levels is advantageous, as these assist in capturing signs of toxicity (1).

A patient's medical history should also be taken into account when interpreting the results of vitamin D assays, and to decipher whether endogenous production of vitamin $\mathrm{D}$ is impaired, as for example co-morbidities such as malabsorptive disorders or advanced diseases of the liver and kidneys affect vitamin D metabolism $(63,64)$. In addition, body composition and exogenous sources of vitamin D should be assessed, including geographical location and lifestyle factors. These can include food sources of vitamin $\mathrm{D}$, as well as habitual level of sun exposure (60). In fact, the interpretation of baseline and follow-up serum 25hydroxyvitamin D concentrations should always consider seasonal variation. Finally, it has been advised that clinicians use certified laboratories (e.g. those that use methods certified to the RMP developed by NIST and Ghent University) where possible.

\section{Conclusion}

Accurate measurement of vitamin D status has profound significance for research studies and for clinical trials, which are used to form evidence-based guidelines. Moreover, clinical decisions with respect to vitamin D treatment for patients hinge on the laboratory analysis of serum 25hydroxyvitamin D concentrations. Currently, the lack of harmony amongst the various vitamin $\mathrm{D}$ analytical techniques and assays is seen as a limitation for studies on vitamin D effects. However, the VDSP holds potential for enabling progress to be made through establishing robust procedures for vitamin D quantification. Until such time comes, research and clinicians alike should take the laboratory-related variabilities into consideration when interpreting vitamin D-related data.

The issues of variability and systematic errors will, however, likely continue in the near future, when more powerful MS instruments will enable routine quantification of additional functional vitamin D metabolites - located further down the vitamin D metabolic pathway - to obtain the full set of meaningful vitamin D status markers and metabolic phenotypes. For example, the ratio of serum 25hydroxyvitamin D to 24-25-dihydroxyvitamin D might offer further insights into vitamin D deficiency status. However, there is no reason to believe that these compounds are not similarly affected by the problems described for 25hydroxyvitamin D. Therefore, further analytical and pathophysiological studies are required in this area before such an approach can be implemented in clinics.

\section{References}

1 Holick MF: Vitamin D deficiency. N Engl J Med 357(3): 266281, 2007.

2 Reichrath J, Zouboulis CC, Vogt T and Holick MF: Targeting the vitamin D endocrine system (VDES) for the management of inflammatory and malignant skin diseases: An historical view and outlook. Rev Endocr Metab Disord 17(3): 405-417, 2016.

3 Scragg R, Stewart AW, Waayer D, Lawes CMM, Toop L, Sluyter J, Murphy J, Khaw KT and Camargo CA Jr.: Effect of monthly high-dose vitamin D supplementation on cardiovascular disease in the vitamin D assessment study: A randomized clinical trial. JAMA Cardiol 2(6): 608-616, 2017.

4 Baron JA, Barry EL, Mott LA, Rees JR, Sandler RS, Snover DC, Bostick RM, Ivanova A, Cole BF, Ahnen DJ, Beck GJ, Bresalier RS, Burke CA, Church TR, Cruz-Correa M, Figueiredo JC, Goodman M, Kim AS, Robertson DJ, Rothstein R, Shaukat A, Seabrook ME and Summers RW: A trial of calcium and vitamin $\mathrm{D}$ for the prevention of colorectal adenomas. N Engl $\mathrm{J}$ Med 373(16): 1519-1530, 2015.

5 Schöttker B, Jorde R, Peasey A, Thorand B, Jansen EH, Groot L, Streppel M, Gardiner J, Ordóñez-Mena JM, Perna L, Wilsgaard T, Rathmann W, Feskens E, Kampman E, Siganos G, Njølstad I, Mathiesen EB, Kubínová R, Pająk A, Topor-Madry R, Tamosiunas A, Hughes M, Kee F, Bobak M, Trichopoulou A, Boffetta P, Brenner $\mathrm{H}$ and Consortium on Health and Ageing: Network of Cohorts in Europe and the United States: Vitamin D and mortality: Meta-analysis of individual participant data from a large consortium of cohort studies from Europe and the United States. BMJ 348: g3656, 2014.

6 Chowdhury R, Kunutsor S, Vitezova A, Oliver-Williams C, Chowdhury S, Kiefte-de-Jong JC, Khan H, Baena CP, Prabhakaran D, Hoshen MB, Feldman BS, Pan A, Johnson L, Crowe F, Hu FB and Franco OH: Vitamin D and risk of cause specific death: Systematic review and meta-analysis of observational cohort and randomised intervention studies. BMJ 348: g1903, 2014.

7 Krause R, Stange R, Kaase H and Holick MF: UV irradiation and pleiotropic effects of vitamin D in chronic kidney disease benefits on cardiovascular comorbidities and quality of life. Anticancer Res 36(3): 1403-1408, 2016.

8 Khaw KT, Stewart AW, Waayer D, Lawes CMM, Toop L, Camargo CA Jr. and Scragg R: Effect of monthly high-dose vitamin D supplementation on falls and non-vertebral fractures: Secondary and post-hoc outcomes from the randomised, doubleblind, placebo-controlled vida trial. Lancet Diabetes Endocrinol 5(6): 438-447, 2017.

9 Barry EL, Peacock JL, Rees JR, Bostick RM, Robertson DJ, Bresalier RS and Baron JA: Vitamin D receptor genotype, vitamin $\mathrm{D}_{3}$ supplementation, and risk of colorectal adenomas: $\mathrm{A}$ randomized clinical trial. JAMA Oncol 3(5): 628-635, 2017.

10 Institute of Medicine (US) Committee to Review Dietary Reference Intakes for Vitamin D and Calcium. 3, Overview of Vitamin D. In: Dietary Reference Intakes for Calcium and Vitamin D. Ross AC, Taylor CL, Yaktine AL and Del Valle HB, (eds.). Washington (DC), National Academies Press (US), 2011. 
11 Holick MF, Binkley NC, Bischoff-Ferrari HA, Gordon CM, Hanley DA, Heaney RP, Murad MH, Weaver CM and Endocrine Society: Evaluation, treatment, and prevention of vitamin D deficiency: An endocrine society clinical practice guideline. J Clinical Endocrin Metab 96(7): 1911-1930, 2011.

12 Spedding S, Vanlint S, Morris H and Scragg R: Does vitamin D sufficiency equate to a single serum 25-hydroxyvitamin D level or are different levels required for non-skeletal diseases? Nutrients 5(12): 5127-5139, 2013.

13 Sempos CT, Vesper HW, Phinney KW, Thienpont LM, Coates PM and Vitamin DSP: Vitamin D status as an international issue: National surveys and the problem of standardization. Scand J Clin Lab Invest Suppl 243: 32-40, 2012.

14 Farrell C, Soldo J, Williams $P$ and Herrmann M: 25Hydroxyvitamin D testing: challenging the performance of current automated immunoassays. Clin Chem Lab Med 50(11): 1953-1963, 2012.

15 Holmes EW, Garbincius J and McKenna KM: Analytical variability among methods for the measurement of 25hydroxyvitamin D: Still adding to the noise. Am J Clin Pathol 140(4): 550-560, 2013

16 Hsu SA, Soldo J and Gupta M: Evaluation of two automated immunoassays for 25-OH vitamin D: Comparison against LCMS/MS. J Steroid Biochem Mol Biol 136: 139-145, 2013.

17 Le Goff C, Peeters S, Crine Y, Lukas P, Souberbielle JC and Cavalier E: Evaluation of the cross-reactivity of 25hydroxyvitamin $\mathrm{D}_{2}$ on seven commercial immunoassays on native samples. Clin Chem Lab Med 50(11): 2031-2032, 2012.

18 Lee JH, Choi JH, Kweon OJ and Park AJ: Discrepancy between vitamin D total immunoassays due to various cross-reactivities. J Bone Metab 22(3): 107-112, 2015.

19 Heijboer AC, Blankenstein MA, Kema IP and Buijs MM: Accuracy of 6 routine 25-hydroxyvitamin D assays: influence of vitamin D-binding protein concentration. Clin Chem 58(3): $543-$ $548,2012$.

20 van den Ouweland JM, Beijers AM, van Daal H, Elisen MG, Steen $G$ and Wielders JP: Evaluation of 3-epi-25hydroxyvitamin $\mathrm{D}_{3}$ cross-reactivity in the Roche Elecsys vitamin D total protein-binding assay. Clin Chem Lab Med 52(3): 373 380,2014

21 Carter GD: Accuracy of 25-hydroxyvitamin D assays: Confronting the issues. Curr Drug Targets 12(1): 19-28, 2011

22 Lensmeyer G, Poquette M, Wiebe D and Binkley N: The C-3 epimer of 25-hydroxyvitamin $\mathrm{D}(3)$ is present in adult serum. $\mathrm{J}$ Clin Endocrinol Metab 97(1): 163-168, 2012.

23 van den Ouweland JM, Beijers AM, van Daal H, Elisen MGLM, Stehen G and Wielders JPM: C3-epimer cross-reactivity of automated 25-hydroxyvitamin D immunoassays. Ned Tijdschr Klin Chem Labgeneesk 38: 136-138, 2013.

24 Jones $G$ and DeLuca HF: High-pressure liquid chromatography: Separation of the metabolites of vitamins $\mathrm{D}_{2}$ and $\mathrm{D}_{3}$ on smallparticle silica columns. J Lipid Res 16(6): 448-453, 1975.

25 El-Khoury JM, Reineks EZ and Wang S: Progress of liquid chromatography-mass spectrometry in measurement of vitamin D metabolites and analogues. Clin Biochem 44(1): 66-76, 2011

26 de la Hunty A, Wallace AM, Gibson S, Viljakainen H, LambergAllardt $\mathrm{C}$ and Ashwell $\mathrm{M}$ : choice of method for measuring 25hydroxyvitamin $\mathrm{D}$ to estimate vitamin $\mathrm{D}$ status for the UK National Diet and Nutrition Survey. Br J Nutr 104(4): 612-619, 2010
27 Volmer DA, Mendes LR and Stokes CS: Analysis of vitamin D metabolic markers by mass spectrometry: Current techniques, limitations of the "gold standard" method, and anticipated future directions. Mass Spectrom Rev 34(1): 2-23, 2015.

28 Volmer DA and Stokes CS: Analysis of vitamin D metabolites by mass spectrometry. In: Encyclopedia of Lipidomics. Wenk MR (ed.). Springer: Dordrecht, 2016.

29 Jessome LL and Volmer DA: Ion suppression: A major concern in mass spectrometry. LC-GC North America 24: 498-510, 2006.

30 Vogeser M, Kyriatsoulis A, Huber E and Kobold U: Candidate reference method for the quantification of circulating 25hydroxyvitamin $\mathrm{D}_{3}$ by liquid chromatography-tandem mass spectrometry. Clin Chem 50(8): 1415-1417, 2004.

31 Qi Y, Geib T, Schorr P, Meier F and Volmer DA: On the isobaric space of 25-hydroxyvitamin D in human serum: Potential for interferences in liquid chromatography/tandem mass spectrometry, systematic errors and accuracy issues. Rapid Commun Mass Spectrom 29(1): 1-9, 2015.

32 Liebisch G and Matysik S: Accurate and reliable quantification of 25-hydroxy-vitamin d species by liquid chromatography highresolution tandem mass spectrometry. J Lipid Res 56(6): 12341239, 2015.

33 Geib T, Sleno L, Hall RA, Stokes CS and Volmer DA: Triple quadrupole versus high resolution quadrupole-time-of-flight mass spectrometry for quantitative LC-MS/MS analysis of 25hydroxyvitamin D in human serum. J Am Soc Mass Spectrom 27(8): 1404-1410, 2016.

34 van den Ouweland JM, Beijers AM and van Daal H: Overestimation of 25-hydroxyvitamin $\mathrm{D}_{3}$ by increased ionisation efficiency of 3-epi-25-hydroxyvitamin $\mathrm{D}_{3}$ in LC-MS/MS methods not separating both metabolites as determined by an LCMS/MS method for separate quantification of 25-hydroxyvitamin $\mathrm{D}_{3}, 3$-epi-25-hydroxyvitamin $\mathrm{D}_{3}$ and 25-hydroxyvitamin $\mathrm{D}_{2}$ in human serum. J Chromatogr B Analyt Technol Biomed Life Sci 967: 195-202, 2014.

35 Stokes CS and Volmer DA: Assessment of 3-epi-25hydroxyvitamin d levels during cholecalciferol supplementation in adults with chronic liver diseases. Appl Physiol Nutr Metab 41(12): 1311-1317, 2016.

36 Müller MJ, Stokes CS and Volmer DA: Quantification of the 3alpha and 3beta epimers of 25-hydroxyvitamin $\mathrm{D}_{3}$ in dried blood spots by LC-MS/MS using artificial whole blood calibration and chemical derivatization. Talanta 165: 398-404, 2017.

37 Goldman MM, Viec KV, Caulfield MP, Reitz RE, McPhaul MJ and Clarke NJ: The measurement of 3-epimer 25-hydroxyvitamin D by mass spectrometry in clinical specimens detects inconsequential levels in adult subjects. J Investig Med 62(4): 690-695, 2014.

38 Carter GD: 25-hydroxyvitamin D: A difficult analyte. Clin Chem 58(3): 486-488, 2012.

39 Lai JK, Lucas RM, Banks E, Ponsonby AL and Autoimmune Investigator $\mathrm{G}$ roup: Variability in vitamin $\mathrm{D}$ assays impairs clinical assessment of vitamin D status. Intern Med J 42(1): 43-50, 2012.

$40 \mathrm{Lu}$ ZX and Sikaris KA: Variability in vitamin D assays impairs clinical assessment of vitamin D status. Intern Med J 42(8): 960961; author reply 961-962, 2012.

41 Ward G, Langguth D and Price L: The DiaSorin Liaison method has not underestimated serum 25-OH-vitamin D levels or misclassified patients with vitamin D deficiency in the Australian population. Intern Med J 42(8): 959-960; author reply 961-952, 2012. 
42 Couchman L, Benton CM and Moniz CF: Variability in the analysis of 25-hydroxyvitamin $\mathrm{D}$ by liquid chromatographytandem mass spectrometry: The devil is in the detail. Clin Chim Acta 413(15-16): 1239-1243, 2012.

43 Carter GD, Carter CR, Gunter E, Jones J, Jones G, Makin HL and Sufi S: Measurement of vitamin D metabolites: An international perspective on methodology and clinical interpretation. J Steroid Biochem Mol Biol 89-90(1-5): 467-471, 2004.

44 Carter GD, Berry JL, Gunter E, Jones G, Jones JC, Makin HL, Sufi S and Wheeler MJ: Proficiency testing of 25-hydroxyvitamin D (25-OHD) assays. J Steroid Biochem Mol Biol 121(1-2): 176179,2010 .

45 Tai SS, Bedner M and Phinney KW: Development of a candidate reference measurement procedure for the determination of 25hydroxyvitamin $\mathrm{D}_{3}$ and 25-hydroxyvitamin $\mathrm{D}_{2}$ in human serum using isotope-dilution liquid chromatography-tandem mass spectrometry. Anal Chem 82(5): 1942-1948, 2010.

46 Stepman HC, Vanderroost A, Van Uytfanghe K and Thienpont LM: Candidate reference measurement procedures for serum 25hydroxyvitamin $\mathrm{D}_{3}$ and 25-hydroxyvitamin $\mathrm{D}_{2}$ by using isotopedilution liquid chromatography-tandem mass spectrometry. Clin Chem 57(3): 441-448, 2011.

47 Mineva EM, Schleicher RL, Chaudhary-Webb M, Maw KL, Botelho JC, Vesper HW and Pfeiffer CM: A candidate reference measurement procedure for quantifying serum concentrations of 25-hydroxyvitamin $\mathrm{D}(3)$ and 25-hydroxyvitamin $\mathrm{D}(2)$ using isotope-dilution liquid chromatography-tandem mass spectrometry. Anal Bioanal Chem 407(19): 5615-5624, 2015.

48 Cashman KD, Kiely M, Kinsella M, Durazo-Arvizu RA, Tian L, Zhang Y, Lucey A, Flynn A, Gibney MJ, Vesper HW, Phinney KW, Coates PM, Picciano MF and Sempos CT: Evaluation of Vitamin D Standardization Program protocols for standardizing serum 25-hydroxyvitamin D data: A case study of the program's potential for national nutrition and health surveys. Am J Clin Nutr 97(6): 1235-1242, 2013.

49 Sarafin K, Durazo-Arvizu R, Tian L, Phinney KW, Tai S, Camara JE, Merkel J, Green E, Sempos CT and Brooks SP: Standardizing 25-hydroxyvitamin D values from the Canadian Health Measures Survey. Am J Clin Nutr 102(5): 1044-1050, 2015.

50 Cashman KD, Dowling KG, Skrabakova Z, Kiely M, LambergAllardt C, Durazo-Arvizu RA, Sempos CT, Koskinen S, Lundqvist A, Sundvall J, Linneberg A, Thuesen B, Husemoen LL, Meyer HE, Holvik K, Grønborg IM, Tetens I and Andersen R: Standardizing serum 25-hydroxyvitamin D data from four Nordic population samples using the Vitamin D Standardization Program protocols: Shedding new light on vitamin D status in Nordic individuals. Scand J Clin Lab Invest 75(7): 549-561, 2015.

51 Cashman KD, Dowling KG, Skrabakova Z, Gonzalez-Gross M, Valtuena J, De Henauw S, Moreno L, Damsgaard CT, Michaelsen KF, Mølgaard C, Jorde R, Grimnes G, Moschonis G, Mavrogianni C, Manios Y, Thamm M, Mensink GB, Rabenberg M, Busch MA, Cox L, Meadows S, Goldberg G, Prentice A, Dekker JM, Nijpels G, Pilz S, Swart KM, van Schoor NM, Lips P, Eiriksdottir G, Gudnason V, Cotch MF, Koskinen S, LambergAllardt C, Durazo-Arvizu RA, Sempos CT and Kiely M23: Vitamin D deficiency in Europe: pandemic? Am J Clin Nutr 103(4): 1033-1044, 2016.

52 Schleicher RL, Sternberg MR, Lacher DA, Sempos CT, Looker AC, Durazo-Arvizu RA, Yetley EA, Chaudhary-Webb M, Maw KL, Pfeiffer CM and Johnson CL: The vitamin D status of the
US population from 1988 to 2010 using standardized serum concentrations of 25-hydroxyvitamin D shows recent modest increases. Am J Clin Nutr 104(2): 454-461, 2016.

53 Binkley N, Dawson-Hughes B, Durazo-Arvizu R, Thamm M, Tian L, Merkel JM, Jones JC, Carter GD and Sempos CT: Vitamin D measurement standardization: The way out of the chaos. J Steroid Biochem Mol Biol 173: 117-121, 2017.

54 Sempos CT, Durazo-Arvizu RA, Binkley N, Jones J, Merkel JM and Carter GD: Developing vitamin D dietary guidelines and the lack of 25-hydroxyvitamin d assay standardization: The everpresent past. J Steroid Biochem Mol Biol 164: 115-119, 2016.

55 Gaksch M, Jorde R, Grimnes G, Joakimsen R, Schirmer H, Wilsgaard T, Mathiesen EB, Njølstad I, Løchen ML, März W, Kleber ME, Tomaschitz A, Grübler M, Eiriksdottir G, Gudmundsson EF, Harris TB, Cotch MF, Aspelund T, Gudnason V, Rutters F, Beulens JW, van 't Riet E, Nijpels G, Dekker JM, Grove-Laugesen D, Rejnmark L, Busch MA, Mensink GB, Scheidt-Nave C, Thamm M, Swart KM, Brouwer IA, Lips P, van Schoor NM, Sempos CT, Durazo-Arvizu RA, Škrabáková Z, Dowling KG, Cashman KD, Kiely M and Pilz S: Vitamin D and mortality: Individual participant data meta-analysis of standardized 25-hydroxyvitamin D in 26916 individuals from a European consortium. PLoS One 12(2): e0170791, 2017.

56 Lucas RM, Gorman S, Black L and Neale RE: Clinical, research, and public health implications of poor measurement of vitamin D status. J AOAC Int 100(5): 1225-1229, 2017.

57 Heaney RP: Vitamin D--baseline status and effective dose. N Engl J Med 367(1): 77-78, 2012.

58 Stokes CS, Grünhage F, Baus C, Volmer DA, Wagenpfeil S, Riemenschneider M and Lammert F: Vitamin D supplementation reduces depressive symptoms in patients with chronic liver disease. Clin Nutr 35(4): 950-957, 2016.

59 Zhao S, Gardner K, Taylor W, Marks E and Goodson N: Vitamin $\mathrm{D}$ assessment in primary care: Changing patterns of testing. London J Prim Care 7(2): 15-22, 2015.

60 Black LJ, Anderson D, Clarke MW, Ponsonby AL, Lucas RM and Ausimmune Investigator G: Analytical bias in the measurement of serum 25-hydroxyvitamin D concentrations impairs assessment of vitamin D status in clinical and research settings. PLoS One 10(8): e0135478, 2015.

61 Alshahrani F and Aljohani N: Vitamin D: Deficiency, sufficiency and toxicity. Nutrients 5(9): 3605-3616, 2013.

62 Sahota O, Mundey MK, San P, Godber IM, Lawson N and Hosking DJ: The relationship between Vitamin D and parathyroid hormone: Calcium homeostasis, bone turnover, and bone mineral density in postmenopausal women with established osteoporosis. Bone 35(1): 312-319, 2004.

63 Stokes CS, Volmer DA, Grünhage F and Lammert F: Vitamin D in chronic liver disease. Liver Int 33(3): 338-352, 2013.

64 Lips P, Goldsmith D and de Jongh R: Vitamin D and osteoporosis in chronic kidney disease. J Nephrol 30(5): 671-675, 2017.

Received October 30, 2017

Revised November 29, 2017

Accepted November 30, 2017 